\title{
Immunohistochemical analysis of Nidogen I expression in epithelial ovarian cancer tissues in comparison to normal ovarian tissues - preliminary findings.
}

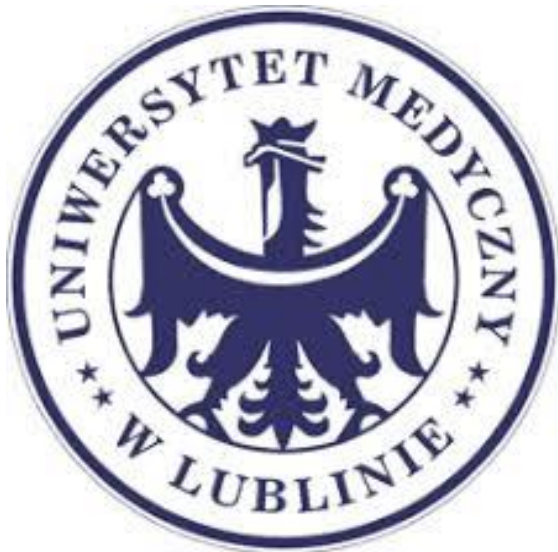

K. Kułak, A. Kułak, P. Ziober-Malinowska, K. Frąszczak, W. Bednarek, J. Kotarski, R. Tarkowski.

Ist Chair and Clinic of Gynaecological Oncology and Gynaecology. Medical Univerisity of Lublin, Poland

\section{Background and Aims}

Late diagnosis of ovarian cancer is one of the most impactful factors regarding mortality of this disease. $70 \%$ of cases are detected and treated in stages III to IV according to latest FIGO staging. Molecular studies of ovarian cancer hope to identify new biomarker proteins enabling an early diagnosis. Nidogen 1 is a basal membrane protein which could be relevant in both development and metastatic mechanism of ovarian cancer.

\section{Methods}

Paraffin embedded epithelial ovarian cancer tissues of 40 patients who underwent surgery in the Ist Chair and Clinic of Gynaecologic Oncology Medical University of Lublin were obtained. As a control we selected 20 normal ovarian tissue samples (paraffin embedded) from patients who underwent surgery due to benign conditions. Monoclonal mouse NID-1 antibodies (R\&D systems) and DAB-H staining was performed according to the manufacturers guidelines. Light microscope was used and the obtained images were analyzed. From each sample 3 sites with most expression were selected and classified according to the localization of the expression (either intracellular, extracellular or no expression).

\section{Positive Nidogen I cytoplasmic expresion in epithelial ovarian cancer}

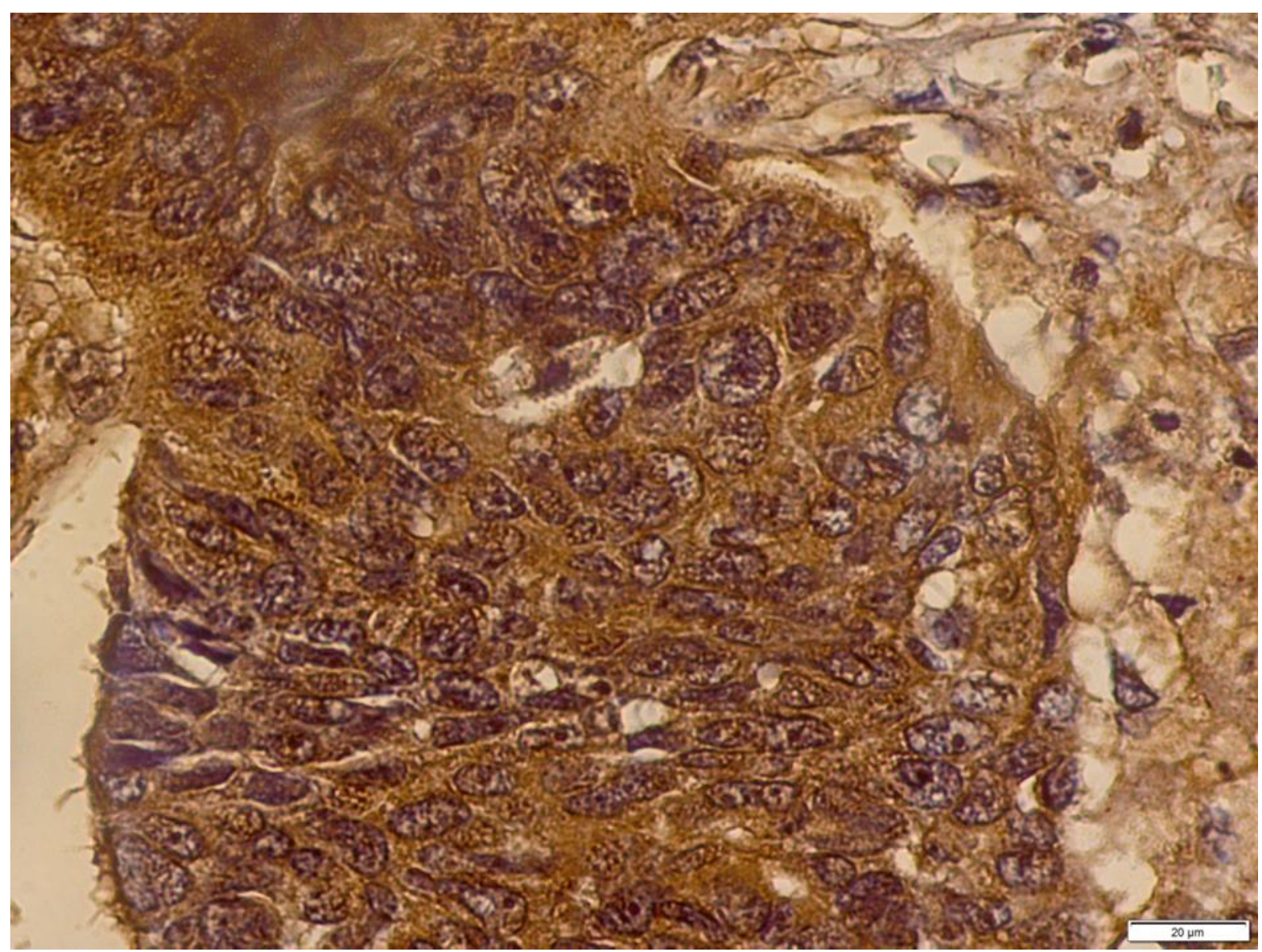

Results

In the group of ovarian cancer samples $83 \% \quad(S D=0,23)$ presented cytoplasmatic, intracellular expression present in 14\% $(S D=0,27)$ and $3 \%(S D=0,09)$ of the viewed sties presented no expression. The control tissues presented $5 \% \quad(\mathrm{SD}=0,1)$ expression for intracellular matrix, $1 \%(S D=0,05)$ for the extracellular matrix and $94 \%(S D=0,11)$ presented no expression, $p>0,001$ (Student's t-test) respectively.

\section{Conclusions}

Epithelial ovarian cancer tissues present a significantly higher expression of the Nidogen 1 protein compared to the normal ovarian tissues. Further studies are required to evaluate its role in ovarian cancer pathogenesis.

Nidogen I distribution in epithelial ovarian cancer tissues

\begin{tabular}{|r|r|r|r|}
\hline $\begin{array}{r}\text { Cytoplasmic } \\
\text { expression }\end{array}$ & $\begin{array}{r}\text { Intracellular } \\
\text { expression }\end{array}$ & No expression & Relevance $(p)$ \\
\hline $0,83+/-0,23$ & $0,17+/-0,27$ & $0,03+/-0,09$ & $P<0,001$ \\
\hline
\end{tabular}

Nidogen I distribution in normal ovarian tissues

\begin{tabular}{|r|r|r|r|}
\hline $\begin{array}{r}\text { Cytoplasmic } \\
\text { expression }\end{array}$ & $\begin{array}{r}\text { Intracellular } \\
\text { expression }\end{array}$ & No expression & Relevance $(\mathfrak{p})$ \\
\hline $0,05+/-0,10$ & $0,01+/-0,05$ & $0,93+/-0,11$ & $\mathrm{P}<0,001$ \\
\hline
\end{tabular}

\section{Positive Nidogen I intercellular expresion in epithelial ovarian cancer}

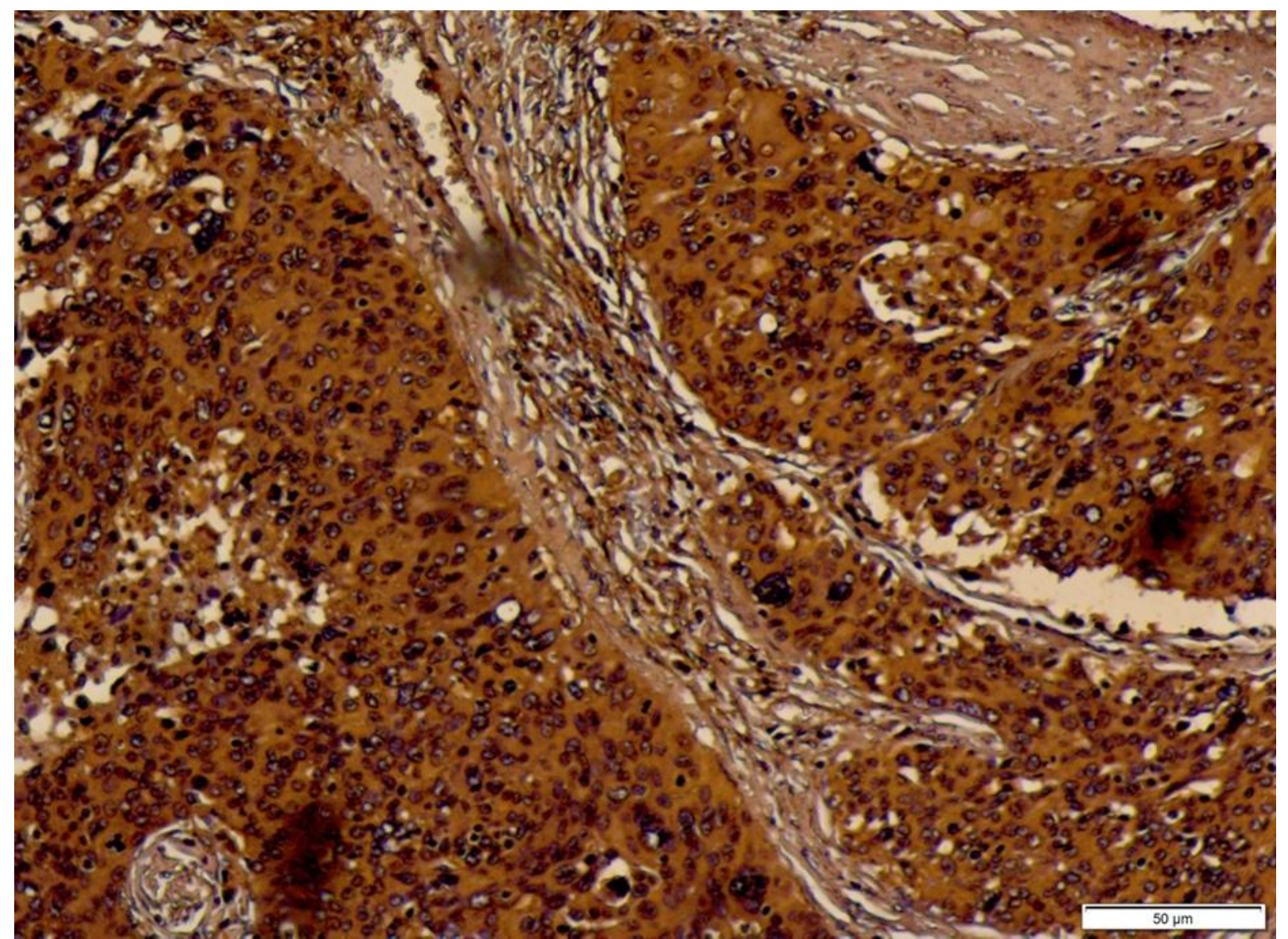

